\title{
Linguagem, sentido e contexto: considerações sobre comunicação e história'
}

\section{Language, meaning and context: notes on communication and history}

\author{
Ana Paula Goulart Ribeiro \\ Mestrado e doutorado em Comunicação e Cultura (UFRJ, 1995, 2000), é professora da Escola de Comunicação da UFRJ com \\ interesse e pesquisa em mídia, memória e história dos meios de comunicação. \\ <goulartap@gmail.com>
}

\section{Bruno Guimarães Martins}

Mestrado em Comunicação (UFMG, 2005); Doutorado em Literatura, Cultura e Contemporaneidade (PUC-Rio, 2013), professor do departamento de Comunicação da UFMG. Dedica-se a pesquisar os meios de comunicação a partir de perspectivas históricas, estéticas e culturais.

< brunomartins@ufmg.br>

\section{Elton Antunes}

Mestrado em Sociologia (UFMG, 1995); doutorado em Comunicação e Cultura Contemporânea (UFBA, 2007), professor da Universidade Federal de Minas Gerais, dedica-se às pesquisas em torno do jornalismo.

<eltunes@uol.com.br>

\section{RESUMO}

O artigo discute as dificuldades de se pensar a noção de contexto histórico no âmbito da pesquisa comunicacional. Dialogamos com proposições das teorias da linguagem que refletem sobre a linguagem, seu caráter performativo e sua materialização nos meios de comunicação, e da teoria da história, especialmente a tradição que persegue continuidades e descontinuidades de uma história cultural. Nossa discussão encaminha-se em torno de duas proposições básicas: 1) a maneira como o conceito de contexto, compreendido de forma automática, impõe uma qualidade referencial ao texto histórico nos estudos do fenômeno comunicativo que oculta, justamente, seus aspectos comunicacionais; 2) a compreensão de que inverter a percepção dos meios de comunicação como parte de um "fundo" sócio histórico para a de uma "figura" de uma história cultural pode fortalecer a reflexão acerca da historicidade no campo da comunicação. Tal movimento poderá contribuir para que a ilusão do contexto seja ultrapassada por uma perspectiva heurística no campo da pesquisa em comunicação.

\section{ABSTRACT}

The article discusses the difficulties of thinking about the notion of historical context in the field of communicational research. We speak with propositions of language theories that reflect on language, its performative character and its materialization in the media, and the theory of history, especially the tradition that pursues continuities and discontinuities of a cultural history. Our discussion is based on two basic propositions: 1) the way in which the concept of context, understood automatically, imposes a referential quality to the historical text in the studies of the communicative phenomenon that exactly hides its communicational aspects; 2) The understanding that reversing the perception of the media as part of a socio-historical "background" to that of a "figure" of a cultural history can strengthen the reflection on historicity in the field of communication. Such a movement may contribute to the illusion of the context being transcended by a heuristic perspective in the field of communication research.

Keywords: Context. Communication. History.

Palavras-chave: Contexto. Comunicação. História.

1 Pesquisa financiada e apoiada por CNPq, Fapemig, Capes, UFMG e UFRJ. 


\section{Introdução}

Em artigo apresentado pela primeira vez em 1965, posteriormente publicado sob o título de "O mito do contexto"1, Karl Popper (2009) dedicouse a combater os argumentos que sustentam o relativismo, doutrina que, aos seus olhos, gera a "impossibilidade de um entendimento mútuo entre culturas, gerações ou períodos históricos diferentes". Para tanto, "em defesa da ciência e da racionalidade", o autor argumenta metaforicamente sobre a prisão intelectual estabelecida pelas regras estruturais de nossa própria língua:

As prisões são os contextos. E aqueles que não gostam de prisões opor-se-ão ao mito do contexto. Acolherão de bom agrado a discussão com alguém de outro mundo, de um outro contexto, pois isso dáIhes a oportunidade de descobrir as amarras que até aí não sentira, ou de as quebrar e assim superar-se a si mesmos. Mas o sair da prisão não é, seguramente, uma questão de rotina: só pode ser o resultado de um esforço crítico e de um esforço criativo (Popper, 2009, p. 98).

De forma análoga à estrutura argumentativa de Popper, o artigo que ora apresentamos pretende questionar a noção de contexto como algo que aprisiona e estabiliza a narrativa histórica do fenômeno comunicacional. Como utopia contemporânea, a despeito da impossibilidade de construção de consensos, acreditamos que confrontar diferentes tempos e culturas, assim como aproximar conceitos de áreas distintas, como é o caso de história e comunicação, pode ser produtivo para o desenvolvimento crítico e criativo da pesquisa acadêmica. Sem a pretensão de encontrar concordância ou simetria, problematizaremos a noção de contexto a partir de três perspectivas - uma abordagem semiolinguística, da história cultural e da comunicação - para desviá-la de relações unidirecionais de causa e efeito. Acreditamos que estes deslocamentos críticos apontem caminhos possíveis para incorporar mais positivamente a historicidade dos meios na compreensão dos fenômenos comunicacionais, e introduzir questionamentos que sejam potentes para desenvolvimento de uma historiografia contemporânea dos meios de comunicação.

2 O título original do artigo é The myth of the framework. Indicamos a diferença de tradução para concordar que as possibilidades (e impossibilidades) da tradução entre línguas, assim como afirma Popper, é exemplar para compreender suas limitações e potencialidades. Entretanto a lição é que se podemos utilizar duas línguas uma vez que podemos aprender outras línguas. 


\section{Contexto como exterioridade constitutiva}

Indicamos assim como perspectiva básica a necessidade de um enfoque relacional da comunicação pensar que as práticas de representação são constituidoras e constituídas pela vida social e que a análise de qualquer significação discursiva irá compreender uma articulação produtiva entre as dimensões proposicional e relacional da linguagem (Guimarães e França, 2006). Uma abordagem tal que indaga sobre as formas de emergência e manifestação do sentido nas interações comunicativas mediadas por formas discursivas específicas, textos que entremeiam os sujeitos mas sem, por um lado, reduzir esses mesmos textos a enunciados simplesmente marcados por sinalizadores morfológicos ou semânticos - "as marcas são uma ínfima parte do iceberg enunciativo", diz Parret (1983, p. 84) - e sem restringir a relação dos sujeitos com esses textos a uma mera faculdade cognitiva alicerçada na produção de referentes. Nesses termos, os textos são vistos como prática de representação e significação do mundo, o constituem e constroem como significado, jamais visto como dado, mas instituído e configurado pela ação linguageira do homem em situação de troca social.

Essa é a perspectiva de abordagens tais como da Semiologia dos Discursos Sociais (Pinto, 1999), ao introduzir os princípios da polifonia e do dialogismo, permite ultrapassar a problemática da Análise dos Discursos como mero instrumento técnico de descrição de textos. Ao retomar a ideia bakhtiniana do discursocomoumaarena, aanálisevisa darcontanãodoconteúdodasmensagens, mas das estratégias discursivas ligadas às relações de força de uma conjuntura dada, eé nesse sentido que inicialmente podemos entender a noção de contexto.

O contexto afigura-se aí como o exterior constitutivo do texto. Algo que não apenas atravessa os discursos, mas que lhes dá vida, o que dá dinamicidade à sua materialidade, o que faz dele uma prática justamente. Prática sempre dinâmica: que se configura e se reconfigura continuamente, que produz sentidos abertos, inacabados, passíveis de diferentes formas de apropriações.

Os discursos de determinadas épocas históricas - principalmente os discursos midiáticos - são espaços privilegiados, onde se travam as lutas sociais. É o campo por excelência do ideológico, onde várias vozes disputam a hegemonia das representações.

A materialidade dos fatos e dos processos só pode se dar via discursos. $E$ é porque os fenômenos se incorporam em matérias significantes que é possível nosso trabalho de pesquisador. A realidade existe; é fato. Mas só através de discursos concretos ela pode ser apreendida. Discurso está sendo entendido aqui, claro, no sentido mais amplo possível. É discurso um ritual, um gesto, um movimento, uma roupa, um olhar. 
Na filosofia da linguagem de Mikhail Bakhtin, o conceito de contexto é essencial, fundamental (1992; 2010). Na dura crítica que faz à linguística saussuriana e ao estruturalismo, ele enfatiza que a significação só existe na compreensão dos sentidos particulares dos signos, na apreensão da orientação que lhe é conferida justamente pelo contexto (institucional ou macrossocial mais amplo) e pela situação precisa (as condições de interação concretas). Bakhtin considera que o centro organizador dos fatos linguísticos não se situa no interior do indivíduo. O sujeito nunca é fonte autônoma de sentido. Todo discurso é determinado "de fora", por situações dialógicas ilimitadas. Este "de fora", o contexto, no entanto, age no interior do próprio discurso como condição constitutiva de sua existência. Não se trata de ambientação ou de "pano de fundo", como já dissemos; trata-se de centro, de "exterior constitutivo".

Se o funcionamento discursivo é regulado do exterior (do interdiscurso), então podemos afirmar que o sujeito é suporte, efeito de linguagem. Ao ignorar a maquinaria da polifonia, ele se crê, entretanto, fonte do sentido. A postulação da interdiscursividade a partir de Bakhtin leva necessariamente a uma teoria da ilusão subjetiva da fala e a um questionamento das teorias linguísticas da enunciação (principalmente o pragmatismo de tradição anglo-saxã).

A polifonia decreta a morte do autor (do locutor) não só porque elimina a ilusão da produção discursiva consciente e individual, mas porque, em última instância, elimina também a noção do sujeito autônomo e homogêneo. Se os sujeitos são constituídos pela linguagem, são efeitos dela, e se a natureza da linguagem é a polifonia e o dialogismo, então, os sujeitos não podem ser senão seres descentrados, clivados, divididos, heterogêneos enfim.

Tal como os discursos, também os sujeitos são polifônicos. Não há centro para eles fora da ilusão e do fantasmagórico. Essa ilusão, claro, é absolutamente normal e necessária e a função do eu psicanalítico é exatamente produzi-la. O eu é a instância que tem o papel de, no imaginário, construir a imagem do sujeito autônomo. E faz isso discursivamente através das formas do que Jacqueline Authier (2004) chama de heterogeneidade mostrada (na contraposição à heterogeneidade constitutiva).

A heterogeneidade constitutiva seria a polifonia formada pelas vozes da história e da cultura, que se fazem presentes em todo o universo discursivo e em relação ao qual o autor não tem controle racional e, às vezes, sequer consciência. A heterogeneidade mostrada é a manifestação explícita da polifonia, localizável na superfície textual. É quando o outro (ou as outras vozes) se inscreve no discurso pela alteração da unicidade aparente da cadeia falada.

A heterogeneidade mostrada pode se dar através de formas marcadas ou não-marcadas. As primeiras ocorrem quando a alteridade é explicitamente 
evocada através de um fragmento que tem, na cadeia discursiva, um estatuto outro, que remete a um outro lugar. É o caso do discurso direto, do discurso indireto, das aspas, do itálico e do metadiscurso do locutor (conjunto de expressões, glosas, retoques, comentários).

As formas não marcadas ocorrem quando o outro é apontado sem marcação unívoca. É o caso do discurso indireto livre, da ironia, da metáfora, dos jogos de linguagem, da paródia, do pastiche e da imitação de estilo.

Ambos os tipos de heterogeneidade mostrada dão forma ao discurso (delimitam seus contornos) ao designarem pontos de heterogeneidade que remetem para aquilo que seria o "lado de fora" do discurso: outros atos enunciativos, a própria língua, outras línguas, outros registros discursivos, outros tipos de discurso, outras modalidades de consideração de sentido, outras palavras, um outro (o interlocutor) (Authier-Revue, 1990, p. 30-31). Todo esse "lado de fora" é entendido aqui por nós como contexto.

O encaminhamento a um exterior determina, por diferença, um interior. Ao explicitar os pontos de divergência com o suposto "lado de fora", o discurso constitui a sua identidade e também a do seu enunciador. Dizer o outro serve, portanto, para circunscrever e afirmar o um.

Aheterogeneidadeconstitutivafunciona comoumaforçadedesagregação tanto do discurso quanto do sujeito. Para combatê-la, este último precisa negociar com ela e faz isso através das formas de heterogeneidade mostrada. Reconhecer o heterogêneo e estabelecer para ele lugares específicos serve, na realidade, para negar a sua onipresença. Em outras palavras, a heterogeneidade mostrada é a forma que o sujeito encontra para proteger a si e ao seu discurso frente a ameaça da heterogeneidade constitutiva. É um "engodo" que o sujeito descentrado, clivado e dividido encontra para afirmar a ilusão de unidade, tanto discursiva quanto subjetiva.

A heterogeneidade constitutiva e a heterogeneidade mostrada designam, assim, duas ordens de realidade diferentes. Uma é o processo real de constituição do discurso, a outra é o processo de representação (não menos real) desse primeiro.

A heterogeneidade mostrada não é, no entanto, deduzível da heterogeneidade constitutiva. Não se pode imaginar um relacionamento simples, de correspondência direta entre essas duas instâncias. Trata-se de duas ordens de realidade irredutíveis, mas (é bom lembrar) articuláveis e solidárias. A heterogeneidade mostrada é, ao mesmo tempo, sintoma e defasada heterogeneidade constitutiva (Authier-Revue, 1990, p. 39).

A descrição das formas de heterogeneidade mostrada torna visíveis os processos de construção imaginária da unidade discursiva, que são, em última 
instância, resultantes da relação que se estabelece com a alteridade. Através da heterogeneidade mostrada, pode-se perceber como os discursos constituem suas identidades, como delimitam seus limites e fronteiras. Através do que é linguisticamente marcado, percebe-se, como as vozes de um discurso dialogam, ou melhor, como se organizam uma em relação a outra no interior do discurso.

Se é na orquestração contrapontual das vozes (nessa dinâmica que remete os discursos para os contextos e os contextos para os discursos) que os sentidos sociais se produzem, nos parece que é, na sua análise, que se encontra uma chave preciosa para a compreensão dos fenômenos sócio históricos. $E$ aqui voltamos a nossa questão do início: a de pensar a teoria da linguagem (em suas várias vertentes) como uma "outra erudição" capaz de fornecer para historiadores ou para nós (estudiosos dos fenômenos comunicacionais) que utilizam os meios de comunicação como vias de acesso à sua historicidade.

\section{Contexto como fonte da história}

Uma vez que perspectivas das ciências da linguagem tanto questionaram o contexto, se faz necessário agora dispô-lo mais diretamente em relação ao discurso histórico. Iniciamos com a afirmação de que os historiadores e nem os pesquisadores que se propõem a trabalhar com a historicidade dos fenômenos comunicacionais partem dos fatos ou dos processos para desenvolver suas reflexões. Partem de documentos, com a ajuda dos quais constroem o que chamamos fatos e processos. Esses materiais exercem um papel central no trabalho acadêmico. Não é à toa que são chamados de fontes. Eles são a origem, a base, de toda a atividade através da qual se reconstrói ou se interpreta as sociedades no tempo. Mas o que são fontes, afinal?

Entendidas em seu sentido mais amplo, qualquer vestígio deixado pelas civilizações passadas ou presentes pode ser fonte. Obviamente não existe fonte em si. Um documento só adquire essa característica quando é abordado pelo pesquisador de uma maneira específica, a partir de um determinado olhar e de determinados tipos de questões.

Os enunciados concretos, passíveis de uma abordagem histórica ou historicizante, se relacionam a diferentes esferas da atividade humana e se apresentam, por isso, sob variadas formas: contratos, textos administrativos, textos legislativos, documentos de origem pública ou privada, escritos científicos, cartas oficiais ou pessoais, etc. Mas também textos jornalísticos, textos literários, artes plásticas, telenovelas, programas de auditório, cinema, música, história em quadrinhos, videogames, posts no Facebook, enfim, qualquer coisa pode hoje se tornar uma fonte histórica. 
Lucien Febvre, já nos primeiros tempos da Escola dos Annales, chamava a atenção para a necessidade de umalargamento da noção de documento.Dizia ele:

\begin{abstract}
A história faz-se com documentos escritos, sem dúvida. Quando estes existem. Mas deve fazer-se sem documentos escritos, quando estes não existem. Com tudo o que a habilidade do historiador lhe permite utilizar para fabricar o seu mel, na falta de flores habituais. Logo, com palavras. Signos. Paisagens e telhas. Com as formas do campo e das ervas daninhas. Com os eclipses da lua e a atrelagem dos cavalos de tiro. Com os exames de pedras feitos pelos geólogos e com as análises de metais feitas pelos químicos. Numa palavra, com tudo o que, pertencendo ao homem, depende do homem, serve o homem, exprime o homem, demonstra a presença, a atividade, os gostos e as maneiras de ser do homem" (Febvre, citado por Le Goff, 1994, p. 540; grifo nosso).
\end{abstract}

Se é verdade que os materiais de pesquisa podem adquirir as formas mais variadas, também é verdade que todos apresentam, em essência, algo em comum: a sua natureza semiológica. Todas as fontes se estruturam segundo certos sistemas de representação e se concretizam através de matérias significantes. Todos os produtos culturais de uma sociedade - um quadro, uma peça teatral, um ritual ou um comportamento humano - sempre se banham no discurso e não podem ser nem totalmente isolados nem totalmente separados dele (Bakhtin, 1986). Tudo sempre passa pela linguagem, seja ela verbal ou não.

A superação da noção positivista de história, já na primeira metade do século passado, possibilitou um alargamento da concepção de fonte. Se antes eram considerados válidos apenas os documentos escritos que o pesquisador pudesse, através da crítica interna e externa, certificar-se da sua autenticidade ou da sua sinceridade e exatidão, agora, qualquer documento - falso ou verdadeiro, sincero ou não - é passível de tornar-se uma fonte para a história ou para o entendimento da dinâmica histórica dos fenômenos sociais (e, em nosso caso mais específico, dos fenômenos comunicacionais).

Sabemos hoje que fatos e processos não são elementos objetivos, observáveis através dos documentos, mas sim produtos de práticas significantes, de práticas sociais. Nesse contexto, as mensagens midiáticas são valorizadas como fonte, mas não podem ser tratadas como meros suportes de transmissão de informações ou como lugar de "revelação", de descrição de eventos que, supostamente, se encontrariam prontos fora deles, em alguma parte do social. A apreensão do real pela mídia pressupõe ação transformadora da linguagem, produção do próprio real. 
Falar em construção do real no discurso não significa assumir, portanto, necessariamente uma posição idealista. Significa simplesmente negar qualquer tipo de separação estanque entre a linguagem e a sua exterioridade constitutiva. E é nesse sentido - enquanto exterioridade constitutiva - que entendemos o conceito de contexto, tema desta nossa reflexão. Contexto não é pano de fundo; não é uma dimensão externa aos fenômenos e que com eles estabelece alguma relação causal. Esse é um ponto essencial.

Mas voltemos ao nosso argumento. Não existe uma realidade prévia a algum tipo de enunciação, já que (repetindo) as instâncias material e discursiva são engendradas em um único e mesmo processo. Um fato já está, no próprio ato de sua realização, impregnado de linguagem, impregnado de significações. Já é, antes mesmo de ser relatado, discurso. Mas há um outro aspecto dessa questão que é importante enfatizar. É que, nas sociedades contemporâneas, a distância que separava o ato e o seu relato, o acontecimento e o seu testemunho, praticamente desapareceu devido à intervenção dos discursos jornalísticos. Referindo-se aos acontecimentos de maio de 1968, Roland Barthes (1970) já chamava atenção para isso:

A palavra informativa do repórter foi tão estritamente misturada ao acontecimento, à própria opacidade do seu presente, que era o seu sentido imediato e consubstancial, o seu modo de aceder a um inteligível instantâneo; isto quer dizer que, nos termos da cultura ocidental, em que nada pode ser privado de sentido, ela era o próprio acontecimento (Barthes, 1970, p. 21).

\section{A fonte dos meios}

Os meios de comunicação vêm sendo, por tudo isso, cada vez mais utilizados como fonte de pesquisa por aqueles que se interessam pela dimensão histórica dos fenômenos sociais e culturais. A valorização da mídia como fonte histórica deve-se à mudança do estatuto do fato e do próprio processo histórico. Quando se admite que ambos são produzidos e não dados, o mais importante deixa de ser o fato ou o processo "em si" e passa a ser a forma pela qual os sujeitos tomam consciência deles e os relatam, assumindo certas posições.

O texto midiático, no entanto, como fonte histórica, deve ser submetido a uma crítica radical. Jacques Le Goff (1994) falava da necessidade de reconhecer em todo documento (testemunho histórico, escolhido pelo pesquisador) um monumento (um ato de poder, uma intencionalidade de perpetuação de uma certa visão do passado).

A noção de documento/monumento deriva de uma posição crítica frente aos documentos, encarados como produto dos jogos de força presentes nas 
sociedades históricas. Como discurso, eles devem ser considerados nas condições concretas em que foram produzidos, ou seja, nos seus contextos - voltando aqui ao nosso conceito-chave. É preciso desmontar os discursos, desestruturar a sua construção, e trazer à tona uma pluralidade de leituras possíveis. A intervenção dos historiadores (ou de outros pesquisadores preocupados com a historicidade) que escolhem o documento, extraindo-o do conjunto dos dados do passado ou do presente, preferindo-o a outros, atribuindo-Ihe um valor de testemunho depende, pelo menos em parte, da sua própria posição na sociedade da sua época e da sua organização mental. O documento não é inócuo. É antes de mais nada o resultado de uma montagem, consciente ou inconsciente, da época, da sociedade que o produziu, do seu contexto produtivo. Mas também, é importante não esquecer, das épocas sucessivas durante as quais continuou a viver, talvez esquecido, e durante as quais continuou a ser manipulado, ainda que pelo silêncio. Resulta do esforço das sociedades históricas para impor ao futuro - voluntária e involuntariamente - determinada imagem de si próprias. Depende, portanto, de suas condições de circulação e de suas formas de apropriação no tempo. Como afirmou Le Goff (1994, p. 547-548): “No limite não existe um documento-verdade. Todo documento é mentira".

A fonte, entendida como documento/monumento, exige a elaboração do que o historiador francês chamou de uma "nova erudição", capaz de transferir esse documento/monumento do campo da memória para o da história. Acreditamos que na elaboração dessa nova erudição, é preciso necessariamente recorrer a uma perspectiva interdisciplinar. E é aqui - nos parece - que a teoria da linguagem pode ser de grande valia.

\section{Perceber a linguagem, desnaturalizar o contexto}

Dialogando com as formulações de uma linguística estrutural Jakobson descreveu com precisão as seis funções da comunicação verbal em seu conhecido esquema apresentado no artigo "Linguística e poética", publicado originalmente em 1960:

\section{— Figura 1: Esquema de Jakobson para as seis funções básicas da comunicação} verbal

$\begin{array}{lll} & \text { REFERENCIAL } & \\ \text { EMOTIVA } & \text { POÉTICA } & \\ & \text { FÁTICA } & \\ & \text { METALINGÜISTICA }\end{array}$

Fonte: Jakobson (2008) 
Apesar de identificar uma predominância hierárquica para a função referencial, justamente aquela com a capacidade de ancorar a mensagem em um contexto, ordenando relações entre remetente e destinatário operadas pelo contatoecompartilhamentodecódigos, oautorrevelaqueaanáliselinguísticanão deve dispensar as demais funções que muitas vezes aparecem como secundárias:

\begin{abstract}
A estrutura verbal de uma mensagem depende basicamente da função predominante. Embora um pendor [Einstellung] para o referente, uma orientação para o contexto - em suma, a chamada função referencial, 'denotativa', cognitiva -, seja a tarefa dominante de numerosas mensagens, a participação adicional de outras funções em tais mensagens deve ser levada em conta pelo linguista atento (Jakobson, 2008, p. 157).
\end{abstract}

Especialmente, ante as cinco funções não referenciais da linguagem, destaca-se a função poética, cuja novidade consiste em revelar que a seleção e combinação de palavras em uma determinada cadeia verbal não dependem apenas das arbitrariedades da língua ou de uma imperativa relação da linguagem-objeto, mas seguem princípios estéticos na composição de seus elementos. Além disso, argumenta Jakobson (2008), tal função não se limita às formas artísticas, como a poesia, mas compõe a estrutura da própria língua. Dessa forma, mesmo que de maneira secundária ou residual, a função poética se encontra presente em qualquer comunicação verbal seja ela a mais pragmática ou "descritiva". Transpondo estas suposições para os interesses do nosso artigo, é necessário perceber que quaisquer discursos que em vários aspectos privilegiem a função de referência, como o discurso historiográfico, muitas vezes utilizado para contextualizar os sentidos um determinado fenômeno comunicacional, se encontram imersos em um processo de composição linguística que sofrem ação de sua função poética.

A função poética identificada por Jakobson (2008) pode ser considerada apenas um exemplo diante de uma série de esforços onde se aglutinam linguagem e filosofia, nomeados por Richard Rorty (1967) em sua influente compilação intitulada The linguistic turn. Para não voltar aos primórdios que parecem sempre passíveis de um novo recuo, vamos mencionar alguns exemplos significativos que surgiram à mesma época. Publicadas em 1962 sob o título How to do things with words, a série de conferências proferidas por Austin parte da constatação de uma onipresente qualidade performativa da linguagem para questionar seu ajuizamento em termos de verdadeiro ou falso. Identificase então aspectos "ilocucionários" de "atos de fala" que se referem à própria 
performance do texto, destaquemos que se trata de um referente distinto da noção convencional de contexto. Tal discussão transbordou os limites do debate filosófico, transfigurando-se em hipóteses de grande alcance como a "crise de representação" descrita por Michel Foucault (2006). Em As palavras e as coisas, publicado pela primeira vez em 1966, o autor desafia a própria história ao elaborar uma arqueologia das ciências humanas, apontando para uma modificação estrutural na linguagem ao longo da modernidade cujo efeito apresenta um progressivo afastamento entre "palavras e coisas", justamente o que estabiliza o discurso em seu contexto referente. Antes de seguir, é importante destacar que a âncora contextual do referente também foi questionada em linguagens menos "arbitrárias", assim como fez E. H. Gombrich ao publicar, em 1960, "Arte e ilusão". No esforço em compreender as transformações nos estilos artísticos a partir de uma perspectiva que considera a percepção da linguagem pictórica, este notável historiador da arte opera um movimento apenas aparentemente contraditório, que parte de análise minuciosa do estilo de artistas específicos para vislumbrar uma perspectiva historicamente ampla da representação. Gombrich (2007) revelou que os artifícios utilizados por artistas em seus esforços mimese, implicam a utilização de sofisticadas técnicas para iludir o espectador. Tais técnicas não tem relação de semelhança com os objetos que representam, mas apontamjustamente para omovimento incessante de transformações dosestilos.

Como passagem ao momento contemporâneo, é importante mencionar, no que tange à história, que uma necessária reflexão historiográfica se desdobrou dos questionamentos advindos de uma filosofia da linguagem apontando como as formas de grafar a história (em seus aspectos gestual e material) interferem nas narrativas que se apresentam como históricas. Nessa direção, lembramos da obra de Hayden White (1973), Metahistory, que incorpora à crítica historiográfica as questões da poética e da estilística para o historiador. Para tanto, foi necessário submeter o discurso histórico a uma análise retórica para "revelar a subestrutura poética do que pretende passar por uma modesta representação em prosa da realidade" (White, 1994, p. 122). De forma similar, Michel de Certeau (1975), em L'ecriture de l'histoire, revelou como a consciência da materialidade do fazer historiográfico, justamente "a escrita da história", apresenta implicações políticas, especialmente nas formas como a linguagem se apropria e cristaliza as múltiplas potências do acontecimento histórico. Neste sentido, a escrita se configura como um palco conflituoso para a história, com batalhas incessantes entre o que se oculta e o que se inscreve. A consciência destes processos revela cores políticas para história, seja para aquele pesquisador que enfrenta o desafio historiográfico dos meios de comunicação, seja para aquele que conscientemente observa a ação dos meios nas configurações e representações 
do acontecimento histórico. Ler (e escrever) histórias, com a atenção voltada não só para o contexto histórico, mas para a linguagem e para a qualidade material dos próprios meios, possibilita a revelação de interditos, de vestígios ocultos, de temporalidades outras. Podemos dizer que o questionamento da posição predominante do contexto estimulou uma sensibilidade estética e material para a história, promovendo um esforço autocrítico que busca resistir às exclusões insinuadas pela própria grafia da história.

\section{A realidade sígnica da comunicação}

Bem conhecemos a tradição de uma sociologia do conhecimento que destaca precisamente o protagonismo da linguagem nas relações intersubjetivas capazes de produzir a "construção social da realidade". Entretanto, assim como destacou Niklas Luhmann, é relevante observar o que caracteriza "a realidade desta construção" (2005, p. 154). Esta perspectiva nos interessa diretamente pois ao buscar compreender a realidade dos meios de comunicação há um deslocamento dos discursos com o que os contextualiza.

Em primeiro lugar, o sentido é constituído pelas operações próprias do comunicar, ou seja, no caso de um texto impresso é necessário escrever, editar, imprimir, publicar, comercializar para que, finalmente, seja possível ler. Importante notar que o processo de realização da comunicação implica em uma lógica recursiva que resulta na reprodução sistemática da comunicação: uma ação comunicacional depreender de uma ação comunicacional e assim por diante. Além disso, em segundo lugar, o que constitui sentido na realidade dos meios de comunicação é a ilusão produzida a partir desta sequência de operações que, por sua vez, produz uma sequência de observações. Voltando ao nosso exemplo, na cadeia do impresso sobrepõem-se diferentes posições de observação: o autor, o editor, o impressor, o comerciante, o leitor. Neste sentido, a realidade dos meios de comunicação se estabelece "em relação àquilo que para eles ou por meio deles aparece como realidade para outros" (Luhmann, 2005, p. 20). A realidade deste processo de construção realizado (e espelhado) pelos meios de comunicação produz um poderoso efeito de "ilusão transcendental". A postura epistemológica elaborada distingue-se de um construtivismo radical, uma vez que não questiona a existência de realidade externa aos meios de comunicação, estabelecendo um construtivismo operacional cujo horizonte de conhecimento configura-se a partir da realidade construída pelos meios de comunicação. Para compreender "como os meios de comunicação constroem a realidade", Luhmann sugere dois movimentos que interessam diretamente a este artigo: 1) "é preciso acima de tudo um período de observação historicamente 
muito (...) dilatado" e; b) "necessita-se de instrumentos teóricos suficientemente abstratos para poder enquadrar a teoria dos meios de comunicação numa teoria geral da sociedade moderna" (2005, p. 25).

Além da perspectiva histórica ampla, o autor formula uma sofisticada teoria que aponta para a centralidade dos meios de comunicação ao identificálos como subsistemas capazes de produzir, simultaneamente "diferenciação autofortificada" e promover acoplagens entre sistemas distintos. O argumento mostra-seespecialmente sedutor para a relação entre comunicação e história pois sugere que as transformações históricas das formas comunicativas afetam todos os outros subsistemas sociais, lembrand o a recomendação do autor de que se faça da"história das formas de comunicação e dos meios de comunicação o substituto funcional para a antiga história em si mesma"(citado por Gumbrecht, 1998, p. 71).

\section{A condição liminar do contexto}

É, pois, o momento de retomar o movimento de "desnaturalização" da noção de conceito. Se os meios de comunicação são compreendidos em sua materialidade sígnica, ou seja, como aquilo capaz de tornar presente algo ausente em algum aspecto ou capacidade, podemos dizer que a comunicação, até mesmo em sua performance face-a-face, promove deslocamentos espaciais e temporais, notando também que os processos de reiteração nos fazem duvidar do suposto caráter originário de qualquer contexto original. Dessa forma podemos apreender, por exemplo, os meios de comunicação como máquinas de produção de anacronias, no sentido apresentado por Rancière:

Nãoexisteanacronismo. Mas modos de conexãoque podemos chamar positivamente de anacronias: acontecimentos, noções, significações que tomam o tempo de frente para trás, que fazem circular sentido de uma maneira que escapa a toda contemporaneidade, a toda identidade do tempo com 'ele mesmo' (Rancière, 2011, p. 49).

Procuramos no mais das vezes "situar" nosso objeto da comunicação na "época a que ele pertence" - eis a nossa ação típica de contextualizar. No Houaiss (2001, p. 41): "erro de cronologia que geralmente consiste em atribuir a uma época ou a uma personagem ideias e sentimentos que são de outra época, ou em representar, nas obras de arte, costumes e objetos de uma época a que não pertencem". No nosso caso sempre pensamos os meios e as textualidades na ordem de uma sucessão, de um encadeamento com "coisas" que vieram 
antes e que explicam aquele "estado de coisas"- e logicamente apontam uma sequência. A acronia remeteria para uma conexão articulada de elementos.

\footnotetext{
"O conceito de 'anacronismo' é anti-histórico porque ele oculta as condições mesmas de toda historicidade. Há história à medida que os homens não se 'assemelham' ao seu tempo, à medida que eles agem em ruptura com o 'seu' tempo, com a linha de temporalidade que os coloca em seus lugares impondo-lhes fazer do seu tempo este ou aquele 'emprego'. Mas essa ruptura mesma só é possível pela possibilidade de conectar essa linha de temporalidade com outras, pela multiplicidade de linhas de temporalidade presentes em 'um' tempo" (Rancière, 2011, p. 47).
}

Se as textualidades midiáticas existem produzindo unidades de sentido em um processo incessante de reabrir e fechar de suas fronteiras, texto e contexto não podem se implicar como pólos ou figuras estáveis. É certo que, em alguma medida nos aproximamos e não podemos ignorar aquilo que Thompson (1995) indicou como a análise sócio histórica, em sua metodologia da hermenêutica de profundidade, em que é preciso observar as situações espaço-temporais, campos de interação, instituições sociais, estrutura social e meios técnicos de transmissão para análise dos fenômenos da comunicação. Isso parece indicar um caminho necessário e incontornável, uma espécie de contextualização histórica básica que a compreensão de todo objeto irá exigir, compreensão essa que radica naquilo que for definido a partir das questões específicas de uma pesquisa. Mas também indica, a partir da reflexão feita até aqui, a necessidade de estarmos alertas para o que nessa chamada contextualização históricosocial às vezes se apaga, pois não condiz ou escapa ao efeito de realidade - de produção da referência - que ela pretende criar.

Nessa esteira, o contexto em uma ideia de historicidade da comunicação implica quenos desvencilhemos de uma abordagem análoga a uma historiografia cientificista, em tudo avessa a uma perspectiva mais "benjaminiana" que, como caracteriza Gagnebin (1994), mostra como, ao contrário de pensar uma relação "extensiva do objeto no tempo, colocado como por acidente num desenrolar histórico heterogêneo à sua constituição" (Gagnebin, 1994, p. 13), , o pensador alemão via também a possibilidade de vislumbrar história e temporalidade, "concentradas no objeto: relação intensiva do objeto com o tempo, do tempo no objeto" (Gagnebin, 1994, p.13). A limitação temporal está, pois, ligada à possibilidade de sondar determinados processos naqueles momentos que parecem ser o da sua origem (e não de sua gênese) e de seu limiar (e não de 
suas fronteiras). A ideia de origem, diferente de gênese, quer apreender o tempo histórico não em termos de cronologia, mas em termos de intensidade. A origem não é um estágio primeiro, mas uma emergência do diferente, um originário que destrói continuidades, que se inscreve no e pelo histórico. 0 limiar, por sua vez, diz de um lugar/tempo de transição e não dos limites. Fala de uma "zona" intermediária onde o fenômeno se produz.

Nesse sentido, a análise comunicacional não busca situar seus objetos em um dado contexto histórico, em certo tempo histórico ou em determinada cronologia. Mas ver como eles são atravessados e convocam distintas temporalidades que os constituem. Assim, seria preciso pensar não apenas os fenômenos comunicacionais no seu contexto temporal, no seu tempo, mas, na perspectiva sugerida por Gagnebin (1994), também segundo o tempo que os conhece, o nosso tempo.

A busca da produção de um tipo de contexto, própria ao conhecimento histórico, supõe procedimentos mínimos de investigação para se aproximar da experiência e transformá-la em conhecimento de certas realidades. A pergunta é pelo que aconteceu. Pensamos que no caso da comunicação, até admitindo a peculiaridade da experiência de mundo que promove, estaríamos propensos a perguntar pelo "acontecendo". Nesse sentido, a historicidade da comunicação, pela própria natureza das práticas que apreciamos, deve ter em conta com certo carinho por abordagens como a de Gumbrecht (1999) para tratar da simultaneidade histórica. Ao produzir um livro sobre o ano de 1926 - que, ele mesmo faz pilhéria, de acordo com a historiografia em geral, foi um ano que não aconteceu "nada" de importante - pretendia uma história não homogênea, não-linear e não-sequencial. Ou, como inferimos de Gagnebin, "os objetos dessa coleta não são anteriormente submetidos aos imperativos de um encadeamento lógico exterior, mas são apresentados na sua unicidade e na sua excentricidade como as peças de um museu" (1994, p.12). Haveria então que se dar conta dos fenômenos comunicacionais em condição liminar, ao mesmo tempo de origem, de limite e ponto de passagem.

Em um segundo movimento, trata-se, na formulação do contexto, da ideia de produzir uma certa "percepção de superfície" - uma impressão geral do estado do mundo, a produção de um presente nos seus termos - com suas questões, objetivos, textos, apropriações. Ao contrário de um afastamento cronológico, produzir uma aproximação, de "fazer presença" como condição de conhecimento dos elementos nos quais radicam a historicidade do fenômeno comunicacional. O contexto, então, aproximar-se-ia a um gesto conceitual de, parafraseando Gagnebin (1994), salvar os fenômenos arrancando-os a uma falsa continuidade. 


\section{Referências}

AUSTIN, J. L. How to do things with words. Cambridge, Massachussets: Harvard University Press, 1962.

AUTHIER-REVUZ, J. Entre a transparência e a opacidade. Porto Alegre: Edipucs, 2004.

AUTHIER-REVUZ, J. Heterogeneidade(s) enunciativa(s). In: Cadernos de estudos lingüísticos, Campinas: UNICAMP - IEL, n. 19, jul./dez.,1990.

BAKHTIN, M. Estética da criação verbal. São Paulo: Martins Fontes, 1992.

Problemas da poética de Dostoiévski. Tradução: Paulo Bezerra. 5 ed. Rio de Janeiro: Forense Universitária, 2010.

CERTEAU, Michel De. L'ecriture de l'histoire. Paris: Gallimard, 1975.

FOUCAULT, M. As palavras e as coisas: uma arqueologia das ciências humanas. São Paulo: Martins Fontes, 2006.

GAGNEBIN, Jeanne Marie. História e narração em Walter Benjamin. São Paulo: Perspectiva: Campinas: Editora da Unicamp, 1994.

GOMBRICH, E. H. Arte e ilusão: um estudo da psicologia da representação pictórica. São Paulo: Martins Fontes, 2007.

GUIMARÃES, César; FRANÇA, Vera. Experimentando as narrativas no cotidiano.

(Orgs.). Na mídia na rua: narrativas do cotidiano. Belo Horizonte: Autêntica, 2006.

GUMBRECHT, H. U. Modernização dos sentidos. São Paulo: Ed. 34, 1998.

Em 1926: vivendo no limite do tempo. Rio de Janeiro: Record, 1999.

HOUAISS, A. Dicionário Houaiss da Língua Portuguesa. Rio de Janeiro: Objetiva, 2001.

JAKOBSON, Roman. Lingüística e comunicação. São Paulo: Editora Cultrix, 2008.

LUHMANN, Niklas. A realidade dos meios de comunicação. São Paulo: Paulus, 2005.

PARRET, Herman. L'énonciation en tant que déictisation et modalisation, Langages. Paris: Walter de Gruyter GmbH \& Co KG, 1983.

PINTO, Milton José. Comunicação e discurso: introdução a análise de discursos. São Paulo: Hacker Editores, 1999.

POPPER, Karl. 0 mito do contexto. Lisboa: Edições 70, 2009. 
RANCIÈRE, Jacques. O conceito de anacronismo e a verdade do historiador. In: SALOMON, Marlon (org.). História, verdade e tempo. Chapecó: Argos, 2011.

RORTY, Richard. The linguistic turn. Recent essas in Philosophical Method. Chicago and London: The University of Chicago Press, 1967.

THOMPSON, John B. Ideologia e cultura moderna. Petrópolis: Vozes, 1995.

WHITE, Hayden. Metahistory: The historical imagination in the nineteenth-century Europe. Baltimore \& London: The Johns Hopkins University Press, 1973.

. Trópicos do discurso: Ensaios sobre a crítica da cultura. São Paulo: Edusp, 1994.

Recebido em: 3/4/2017

Aceito em: 20/4/2017

Endereço dos autores:

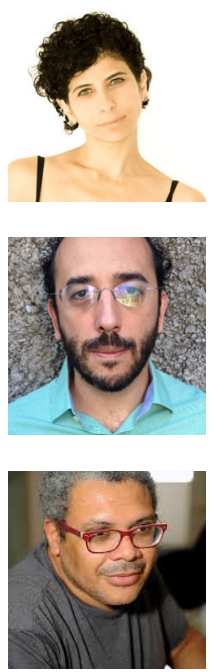

Ana Paula Goulart Ribeiro <goulartap@gmail.com>

Escola de Comunicação da UFRJ

Av. Pasteur, 250 - Praia Vermelha

22290-240 - Rio de Janeiro (RJ) - Brasil

Bruno Guimarães Martins <brunomartins@ufmg.br>

Universidade Federal de Minas Gerais -UFMG

Faculdade de Filosofia e Ciências Humanas da UFMG - Fafich

Departamento de Comunicação Social

Avenida Antônio Carlos, 6627 - Campus Pampulha

31270-901 - Belo Horizonte (MG) - Brasil

Elton Antunes <eltunes@uol.com.br>

Universidade Federal de Minas Gerais -UFMG

Faculdade de Filosofia e Ciências Humanas da UFMG - Fafich

Departamento de Comunicação Social

Avenida Antônio Carlos, 6627 - Campus Pampulha

31270-901 - Belo Horizonte (MG) - Brasil 